Research Paper

\title{
EZH2/Bcl-2 Coexpression Predicts Worse Survival in Diffuse Large B-cell Lymphomas and Demonstrates Poor Efficacy to Rituximab in Localized Lesions
}

Yujie Deng ${ }^{\#}$, Xiaohui Chen ${ }^{\#}$, Chuanzhong Huang ${ }^{3}$, Gang Chen ${ }^{4}$, Fangfang Chen ${ }^{4}$, Jianping Lu ${ }^{4}$, Xi Shi ${ }^{1}$, Cheng $\mathrm{He}^{4}$, Zhiyong Zeng'5, Yanhua Qiu 6 , Junqiang Chen ${ }^{7}$, Rongbo Lin ${ }^{8}$, Yanping Chen ${ }^{4}$, Junmin Chen ${ }^{5 凶}$

1. Department of Chemotherapy, The First Affiliated Hospital of Fujian Medical University, Fuzhou, China

2. Department of Thoracic Surgery, Fujian Cancer Hospital \& Fujian Medical University Cancer Hospital, Fuzhou, China

3. Laboratory of Immuno-Oncology, Fujian Cancer Hospital \& Fujian Medical University Cancer Hospital, Fuzhou, China

4. Department of Pathology, Fujian Cancer Hospital \& Fujian Medical University Cancer Hospital, Fuzhou, China

5. Department of Hematology and Rheumatology, The First Affiliated Hospital of Fujian Medical University, Fuzhou, China

6. Department of Medical Imaging, Grade 2014, Fujian Medical University, Fuzhou, China

7. Department of Thoracic Radiotherapy, Fujian Cancer Hospital \& Fujian Medical University Cancer Hospital, Fuzhou, China

8. Department of Gastrointestinal Oncology, Fujian Cancer Hospital \& Fujian Medical University Cancer Hospital, Fuzhou, China

\# These two authors contributed equally to this paper.

$\triangle$ Corresponding author: Junmin Chen, MD, Ph.D, Email: drchen_cn@sina.com. Department of Hematology and Rheumatology, The First Affiliated Hospital of Fujian Medical University, No. 20 Chazhong Rd. Taijiang District, Fuzhou 350005, Fujian Province, P. R. of China

(C) Ivyspring International Publisher. This is an open access article distributed under the terms of the Creative Commons Attribution (CC BY-NC) license (https://creativecommons.org/licenses/by-nc/4.0/). See http://ivyspring.com/terms for full terms and conditions.

Received: 2018.09.09; Accepted: 2019.04.20; Published: 2019.05.12

\begin{abstract}
Enhancer of zeste homolog $2(\mathrm{EZH} 2)$ and $\mathrm{Bcl}-2$ gene rearrangement or protein upregulation played pivotal roles in the carcinogenesis of various malignancies including lymphomas. However, $\mathrm{EZH} 2 / \mathrm{Bcl}-2$ expression pattern and its clinicopathologic/prognostic significance in diffuse large B-cell lymphoma (DLBCL) remain unclear. To identify the association among $E Z H 2, B c l-2$, clinicopathologic parametres in DLBCL, $2 \mathrm{DLBCL}$ patient sets (test cohort, $n=85$; validation cohort $\mathrm{n}=51$ ) and $\mathrm{DLBCL}$ cell lines were studied by tumor tissue microarray (TMA), immunohistochemistry and western blot. The optimal cut-off of EZH2 was determined by X-tile program from test cohort, as was verified in validation cohort. The prognostic significance was determined via Kaplan-Meier survival estimates and log-rank tests. Consequently, EZH2 and $\mathrm{Bcl}-2$ expression were both enhanced and positively correlated with each other $(P=0.001)$ in both $\mathrm{DLBCL}$ patients and cell lines. $\mathrm{EZH} 2 / \mathrm{Bcl}-2$ coexpression was associated with poor overall survival $(\mathrm{OS})$ and progression-free survival (PFS) in all DLBCL patients (all $P<0.05$ ). Univariate analyses revealed that EZH $2 / B c l-2$ coexpression correlated to worse objective response rate (ORR), shorter OS and PFS in DLBCL patients treated with RCHOP while multivariate analysis indicated that only elevated LDH level $(P=0.001)$ and presence of $B$ symtom $(P=0.008)$ rather than $E Z H 2 / B c l-2$ coexpression were associated with worse OS. No survival benefit from rituximab regimen had been demonstrated in the early-staged DLBCL patients with EZH2/Bcl-2 coexpression. While in the subgroup of III-IV stage, $\mathrm{RCHOP}$ regimen showed obvious better OS and PFS than CHOP $(P=0.039$ and 0.005$)$. In conclusion, EZH2/Bcl-2 coexpression defines unrecognized subgroup of DLBCL patients with distinct epigenetic phenotype and worse outcome.
\end{abstract}

Key words: diffuse large B-cell lymphoma $\cdot \mathrm{EZH} 2 \cdot \mathrm{Bcl}-2$ prognosis rituximab

\section{Introduction}

Diffuse large B-cell lymphomas (DLBCL) are the major subtype of lymphoid neoplasms in adults, accounting for about $30 \%$ of non-Hodgkin's lymphomas (NHL) diagnosed annually $[1,2]$. 
Chemotherapy, usually CHOP regimen (cyclophosphamide, doxorubicin, vincristine and prednisolone) combined with or without immunotherapy (anti-CD20 monoclonal antibody, rituximab) has transformed the aggressive disease into curable one [3], resulting in an obvious survival benefit and turning out as the mainstay of standard treatment $[4,5]$. Although some patients shared the same staging or international prognostic index (IPI) scores, their clinical outcomes varied a lot. Tumor heterogeneity had claimed a demand of subdivision of DLBCLs into morphological variants, molecular and immunophenotypic subgroups and distinct disease entities. Under these sophisticate circumstances, specific biomarkers to discriminate the higher risk individuals would be greatly necessary, which would inevitably facilitate the selection of proper therapeutic strategies and prediction of the outcome of DLBCLs. Recent studies had shed light on the important roles that epigenetic parameters like histone modifications and DNA methylation had played in the onset and development of lymphoid neoplasms and might provide clues to novel therapeutic regimens for DLBCL[6-8].

Enhancer of zeste homolog2 (EZH2), the histone methyltransferase and main subunit of polycomb repressive complex 2 (PRC2) that mediates epigenetic silencing of target genes via trimethylating histone $\mathrm{H} 3$ at lysine 27 (H3K27me3) at the presence of other subunits like embryonic ectoderm development (EED), suppressor of zeste 12 (SUZ12) and retinoblastoma binding protein (RBBP4/7), had been found overexpress in a variety of malignancies and turned out to be closely associated with high proliferation rate and aggressive tumor subgroups, resulting in worse clinical outcome thereafter [9-12]. Bcl-2, a well-studied anti-apoptotic factor and vital prognostic marker in NHL, was demonstrated to closely correlate with chemotherapy resistance [13]. Interestingly, EZH2 mutation and activation is often present in Bcl-2-rearranged DLBCL patients [14, 15], independent of cell-of-origin (COO) and EZH2 codon 641 mutation [7]. Further, the IGH-Bcl-2 rearrangement often results in overexpression of the Bcl-2 oncoprotein in B-cell lymphomas [16]. Although EZH2 overexpression is prevailing in human solid malignancies [11], the role of association with EZH2 and Bcl-2 in pathogenesis of lymphoid malignancies still requires further elucidation. Our previous study firstly determined high expression of $\mathrm{H} 3 \mathrm{~K} 27 \mathrm{me} 3$ as an independent risk factor in DLBCL patients [17], and secondly demonstrated patients with low EZH2 level in $\mathrm{RCHOP}$ regimen subgroup exhibited better PFS and OS[18]. We thus hypothesized that EZH2, the methyltransferase of H3K27, together with Bcl-2, may be a possible candidate biomarker in the DLBCL patients on the basis of the previous findings regardless of its $\mathrm{COO}$.

In the present study, we identified the expression of EZH2 and Bcl-2 with immunohistochemistry (IHC) in de novo DLBCL patients of both test cohort $(n=85)$ and validation cohort $(n=51)$, finding that expression of EZH2 was closely correlated with Bcl-2 and their coexpression was associated with poor prognosis especially in the RCHOP treatment group. Furthermore, in EZH2/Bcl-2 coexpression DLBCL patients with advanced stages, RCHOP regimen may obviously prevail over CHOP in the therapeutic efficacy.

\section{Materials and methods}

\section{Cell lines culture}

Human DLBCL cell lines TMD8, HBL-1, Ly1 and Ly8 were from Fudan University Cancer Hospital. Human colon cancer cell line HCT116 used as positive control in this study was purchased from the Cell Bank of Chinese Academy of Sciences (Shanghai, China). All cell lines were maintained in Dulbecco's modified Eagle's medium (DMEM) supplemented with $10 \%$ fetal bovine serum (FBS) at $37^{\circ} \mathrm{C}$ containing $5 \% \mathrm{CO} 2$.

\section{Isolation of human peripheral blood lymphcytes}

After taking $1 \mathrm{ml}$ of heparin-anticoagulated human peripheral blood and $2 \mathrm{ml}$ of Hanks solution, it was slowly added along the wall to a tube containing $4 \mathrm{ml}$ of lymphocyte separation solution, then centrifuged at $2000 \mathrm{r} / \mathrm{min}$ for $20 \mathrm{~min}$, and the capillary was extended into the mononuclear cell layer and gently sucked out all the cells along the tube wall. Then, it was washed twice with Hanks solution, centrifuged at $1500 \mathrm{r} / \mathrm{min}$ for $10 \mathrm{~min}$ each time, and then fully lysed by adding a certain amount of cell lysate. The protein concentration was measured by BCA method and then stored frozen at $-80^{\circ} \mathrm{C}$.

\section{Patients and clinical data}

Test cohort containing 85 (from January 2006 to December 2008) and validation cohort consisted of 51 cases (from May 2010 to May 2016) de novo DLBCL patients treated with RCHOP or CHOP regimen and 5 lymphadenitis tissues at Fujian Cancer Hospital \& Fujian Medical University Cancer Hospital were included in this study. All DLBCL cases were diagnosed in accordance with the World Health Organization (WHO) classification criteria[19]. None had received preoperative chemotherapy or radiation prior to biopsy. All lymph nodes (LNs) were examined by biopsy. In the test cohort, detailed 
patients' clinicopathologic data like name, age, sex, ECOG (Eastern Cooperation Oncology Group), B symptoms, extranodal sites, lactate dehydrogenase (LDH) level, Ann-Arbor stage, IPI (International Prognostic Index) score and Hans classification were collected. However, in the validation cohort, only patients' name age, sex, date of diagnosis, status and date of death were collected. Clinical parameters and follow-up data obtained from hospital records were reviewed retrospectively. Overall survival (OS) of test cohort and validation cohort was both defined as from the date of diagnosis until death or last follow-up time, while last follow-up date varied, i.e., February 14, 2018 and December 26, 2018, respectively. Progression-free survival (PFS) of test cohort was calculated from the time of diagnosis to the first time of progression or relapse. PFS of validation cohort was not available. Ethical approval was obtained from the research ethics committee of Fujian Medical University Cancer Hospital, and informed consent was obtained from each patient.

\section{Treatment and response evaluation}

In the test cohort, CHOP regimen was administered in 44 patients (pre-rituximab era) and $\mathrm{R}-\mathrm{CHOP}$ in 41 patients (post-rituximab era). CHOP regimen was as followed: cyclophosphamide, 750 $\mathrm{mg} / \mathrm{m}^{2}$, doxorubicin, $50 \mathrm{mg} / \mathrm{m}^{2}$, vincristine, 1.4 $\mathrm{mg} / \mathrm{m}^{2}$, and prednisolone, $100 \mathrm{mg}$, daily, on days 1-5. Forty-one patients with a combination of rituximab $\left(375 \mathrm{mg} / \mathrm{m}^{2}\right.$ on day 1 of each chemotherapy cycle) and $\mathrm{CHOP}(\mathrm{RCHOP})$ on days 2-6. These regimens were repeated every 3 weeks for a total of $4-8$ cycles. At the point of recurrence a variety of secondary regimens at the discretion of the treating physician were administered.

In the validation cohort, however, $\mathrm{CHOP}$ was given in 19 patients, RCHOP was administered in 20 patients, EPOCH was used in 6 patients, and other regimens were taken in 6 patients.

Tumor responses were assessed at the end of treatment and classified as complete response (CR), partial response (PR), stable disease (SD) or progressive disease (PD) according to the International Workshop Criteria [20].The objective response rate (ORR) included CR and PR rates.

\section{Tissue microarray and immunohistochemistry}

Hematoxylin-eosin-stained slides from all DLBCL cases were reviewed, non-necrosis areas with the reprensentatively highest tumor cell were selected for tissue microarray (TMA) construction. The TMA was constructed according to a method described previously[17, 21, 22]. Immunohistochemistry (IHC) studies for a variety of markers were performed on 4 $\mu$ TMA sections. IHC of EZH2 [1:400, Catalogue No: ab191080, Clone No: EPR9307(2), Abcam, Cambridge, UK], Bcl-2 (1:100, Catalogue No: ab692, Clone No: 100/D5, Abcam, Cambridge, UK), H3K27me3 (1:200, Catalogue No: 9733, Clone No: C36B11, Cell Signaling Technology, MA, USA), Ki-67 (1:200, Catalogue No: 4400, Clone No: MIB1, Cell Signaling Technology, MA, USA), CD10 (1:100, MAB-0668, Fuzhoumaixin), Bcl-6 (1:100, MAB0598, Fuzhoumaixin) and MUM1 (1:200, MAB-0573, Fuzhoumaixin) were performed using the Autostainer Link 48 (Dako).

The stainings were evaluated by using a semi-quantitative immunoreactive score system (IRS) according to the method described in the study by Remmele and Stollberg [23, 24]. At least 5 high-power fields and more than 2,000 cells were calculated in each case with a light microscope (Olympus Optical CX41). Multiplying the percentage of positive tumor cells in five gradations $(0$, no positive cells; $1,<10 \%$ positive cells; $2,10-50 \%$ positive cells; $3,50-80 \%$ positive cells; and $4, \geqq 80 \%$ positive cells) with an intensity scale ( 0 , no staining; 1 , mild; 2 , moderate; and 3, intensive), and the final score ranged from 0-12. An arithmetic mean was calculated from the IRS of each slide. Staining results were examined by two observers masked to clinicopathologic data. Another reading by a third observer was needed to reach a consensus when there was a significant discrepancy between initial readings.

The samples were categorized into low and high expression subgroups based on the cut-off value of EZH2 (immunostaining score $=6$ ) established via X-tile plots according to the survival data [25]. The primary end point used in the determination of cutoff value was OS. Cut-off values for Bcl-2 was defined as 50\% and $\mathrm{Ki}-67$ was $75 \%$, as was referred to the previous studies [26, 27].

\section{Western blot analysis}

The protein expression of EZH2, H3K27me3 and Bcl-2 were determined by western blot (WB) analysis. It should be noted that in the WB analysis, in addition to 4 DLBCL cell lines, colon cancer cell line HCT116 was used as positive control and normal human lymph node (nLN) as well as lymphocyte isolated from normal human peripheral blood were used as negative controls. Briefly, total protein was extracted from HCT116, peripheral blood lymphocytes, nLN and DLBCL cell lines (TMD8, HBL-1, Ly1 and Ly8) and the protein concentration was determined by bicinchoninic acid (BCA) assay. An amount $25 \mu \mathrm{g}$ of total protein was separated on a 10\% SDS-PAGE gel, then transferred to the nitrocellulose (NC) membrane for $1 \mathrm{~h}$ at $60 \mathrm{~V}$ in transfer buffer. The membrane was then blocked with $5 \%$ nonfat milk for $4 \mathrm{~h}$ at room 
temperature, and incubated with 1:1000 primary rabbit anti-human EZH2 monoclonal antibody, mouse anti-human Bcl-2 monoclonal antibody, rabbit anti-human H3K27me3 monoclonal antibody overnight at $4^{\circ} \mathrm{C}$ on a gentle shaker. Following washing with TBST $(20 \mathrm{mmol} / \mathrm{l}$ Tris- $\mathrm{HCl}, 150 \mathrm{mmol} / \mathrm{l}$ $\mathrm{NaCl}$ and $0.05 \%$ Tween-20; $\mathrm{pH} 7.4$ ) three times, for 10 min each time, the membrane was incubated in 1:4000 anti-rabbit HRP-conjugated IgG antibody (catalogue no: 7074S) or anti-mouse HRP-conjugated IgG antibody (catalogue no: 7076S) (both from Cell Signaling Technology, Inc.) at room temperature for 1 $\mathrm{h}$. The membrane was then washed three times for 10 min with TBST buffer $(20 \mathrm{mmol} / 1$ Tris- $\mathrm{HCl}, 150$ $\mathrm{mmol} / 1 \mathrm{NaCl}$ and $0.05 \%$ Tween-20; $\mathrm{pH}$ 7.4) and visualized with the SuperSignal West Pico kit (Thermo Fisher Scientific).

\section{Statistical analysis}

Patients' characteristics and the association between tested markers and clinicopathological features of the patients were compared using Pearson's $\chi^{2}$ analysis or Fisher exact test as appropriate. Survival functions were estimated using the Kaplan-Meier method and compared using the log-rank test. The Cox proportional hazard model was used to evaluate the association between various markers and patient's survival. Univariate and multivariate analyses were determined by Cox regression. A p-value $<0.05$ was considered statistically significant. Statistical analysis of the data was performed using statistical processing software SPSS version 18.0 (SPSS Inc., Chicago, IL, USA). The X-tile software program (Version 3.6.1; Yale University School of Medicine, New Haven, CT, USA) as described previously[25] was used to determine the best threshold value of EZH2 for classifying samples into groups of high and low expression.

\section{Results}

\section{Patients' demographic characteristics}

Patients' characteristic data of test cohort were listed in Table 1. Follow-up duration ranged from 2.6 to 129.6 months, with an average of 70.6 months. The average age was 49.4 y.o (24-78 y.o.) and the number of patients less than and above 60 y.o. was 64 and 21. There were more male patients than female $(65.9 \%$ vs. $34.1 \%)$ in the study. seventy-eight patients' ECOG was lower than 2 and only $7 \geq 2$. Thirty-seven patients were present with $B$ symptom and the other 48 without. Extranodal sites involvement $<2$ was present in 68 individuals. Elevated LDH level was present in 52 patients. All patients were classified according to the Ann-Arbor stage and Hans classification[28], with 42 patients early stage ( I - II ) and 43 advanced (III-IV) and 17 GCB and 68 non-GCB. Sixty cases' IPI score varied within $0-2$ and the other 25 within 3-5. High Ki-67 expression was demonstrated in 57 cases and low expression in 28. Fifty-four suffered from disease relapse at the point of follow-up while the other 31 still healthy.

As for the data of validation cohort, however, there were 29 males and 22 females. Age ranged from 22 - 84 years old and the median age was 54 years old. Follow-up duration ranged from 3.3 to 108.5 months, with an average of 59.4 months.

\section{TMA building and immunohistochemical staining}

In both test cohort and validation cohort, the samples from the the new recipient TMA paraffin blocks were all complete and clear to observe. The TMA was arranged tidily without floating or shifting. Immunostaining for EZH2, Bcl-2 and $\mathrm{Ki}-67$ were observed predominantly in the cell nuclei or membrane (representative staining patterns were shown in Fig. 1A-H) and the frequency of immunopositive cells ranged from $0 \%$ to $100 \%$. Significant difference of EZH2 IRS existed between patients with high and low level of Bcl-2. That's, patients with higher level of Bcl-2 expression obviously demonstrated higher EZH2 IRS $(P<0.05$, Fig. 1I).

\section{Western blot of DLBCL cell lines}

Expression of EZH2, H3K27me3 and Bcl-2 at protein level in DLBCL cell lines were further determined by western blot, indicating enhanced expression of $\mathrm{EZH} 2, \mathrm{H} 3 \mathrm{~K} 27 \mathrm{me} 3$ and $\mathrm{Bcl}-2$ in all DLBCL cell lines of TMD8, HBL-1 Ly1 and Ly8, compared with that in normal human lymphocyte of peripheral blood and normal lymph node (nLN), and human colon cancer cell line HCT116 was used as positive control (Fig. 1J). The gray scale ratios of EZH2, H3K27me3 and Bcl-2 to GAPDH in HCT116, Lymphocyte, nLN, TMD8, HBL-1, Ly1 and Ly8 were "1.63, 0.31, 0.24, 0.79, 1.10, 0.94 and 2.22", "1.39, 0.29, $0.21,0.94,0.85,1.39$ and 1.65 " and "1.33, 0.15, 0.14, $1.20,0.74,1.67$ and $1.96 "$, respectively. 

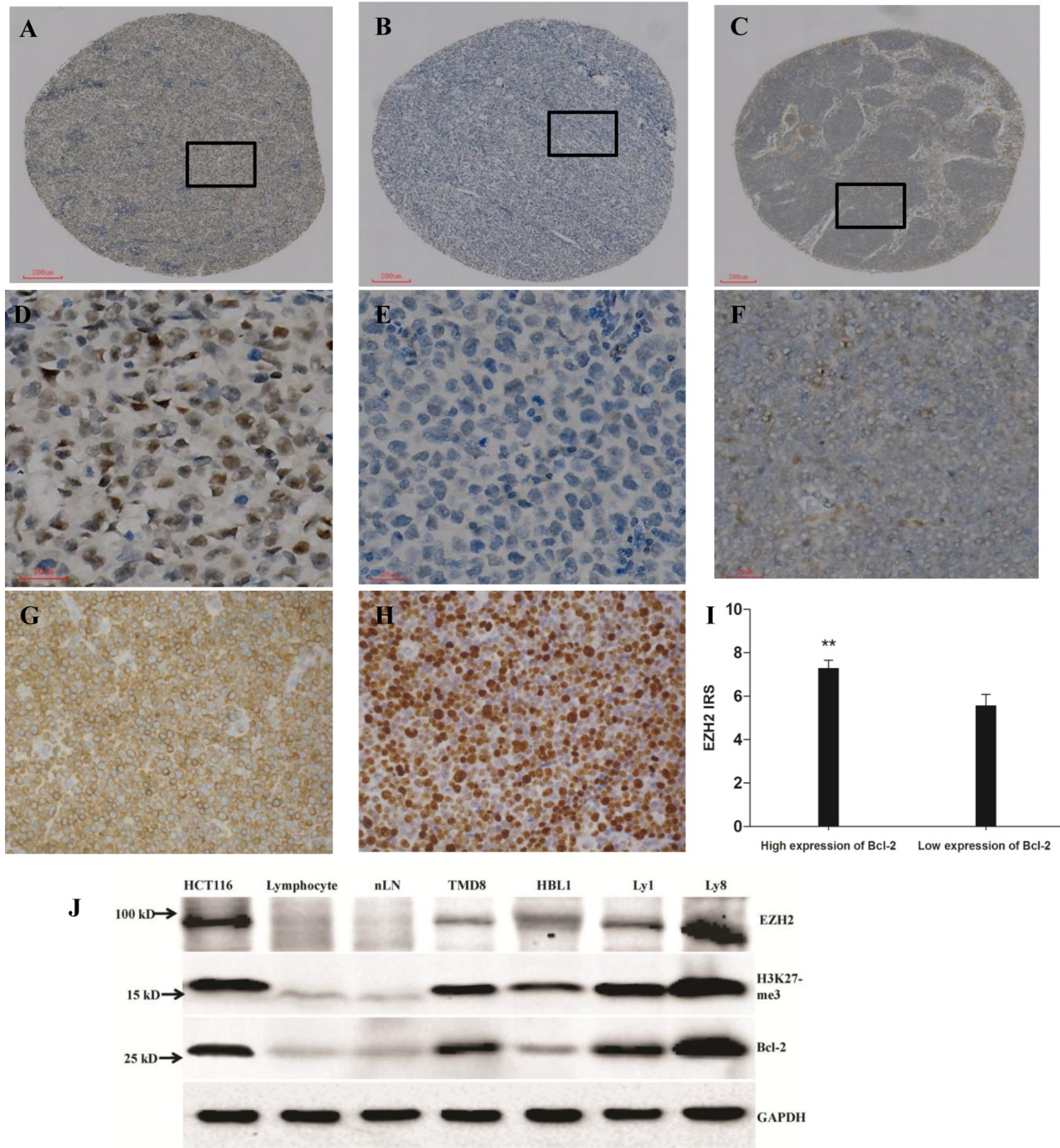

Figure 1. Expression of $\mathrm{EZH} 2, \mathrm{Bcl}-2$ and $\mathrm{Ki}-67$ in diffuse large $\mathrm{B}$-cell lymphoma (DLBCL) and normal lymph node $(\mathrm{nLN})$ tissues, scale bar $=200 \mu \mathrm{m}$ for $\mathrm{A}-\mathrm{C}$ and scale bar=20 $\mu \mathrm{m}$ for D-H. (A). High expression of EZH2 in DLBCL with more than $90 \%$ tumor cells intensively stained by EZH2 antibody in nuclei; (B). Negative immunostaining of EZH2 in DLBCL; (C). No EZH2 staining in nLN. (D-F). High-power images of the areas demarcated in boxes in A-C. (G-H). Positive immunostaining of $\mathrm{Bcl}-2$ and $\mathrm{Ki}-67$ in $\mathrm{DLBCL}$ tissues. $\mathrm{Bcl}-2$ expression exhibited a cytoplasmic pattern and $\mathrm{Ki}-67$ showed a distinct nuclear pattern. (l) Correlation between expression of EZH2 and Bcl-2 in DLBCL. The staining score of EZH2 was significantly higher in high Bcl-2 expression patients compared to those of low Bcl-2 expression (7.29 \pm 0.36 and 5.58 \pm 0.50 , respectively, $P=0.005)$. (J) EZH2, H3K27me3 and Bcl-2 protein expression was detected by western blot in colon cancer cell line HCT116, human peripheral blood lymphocyte, normal lymph node $(n L N)$ and 4 DLBCL cell lines (TMD8, HBL-1, Lyl and Ly8). Lysates from the positive control HCT116 (lane 1), and tumor cell lines (lanes 4-7) had much higher EZH2, H3K27me3 and Bcl-2 immunoreactivity than normal human peripheral blood lymphocyte (lane 2) and $\mathrm{nLN}$ tissue (lane 3). 
Table 1. Association of $\mathrm{EZH} 2$ and $\mathrm{Bcl}-2$ expression with clinicopathologic parameters in test cohort DLBCL patients.

\begin{tabular}{|c|c|c|c|c|c|c|c|c|c|c|}
\hline \multirow[t]{2}{*}{$\begin{array}{l}\text { Variable } \\
\text { s }\end{array}$} & \multirow[t]{2}{*}{$\begin{array}{l}\text { All } \\
\text { cases }\end{array}$} & \multicolumn{2}{|c|}{ EZH2 } & \multirow[t]{2}{*}{$P$} & \multicolumn{2}{|l|}{ Bcl-2 } & \multirow[t]{2}{*}{$P$} & \multicolumn{2}{|c|}{$\begin{array}{c}\mathrm{EZH} 2 / \mathrm{Bcl}-2 \\
\text { coexpression }\end{array}$} & \multirow[t]{2}{*}{$P$} \\
\hline & & High & Low & & High & Low & & Yes & No & \\
\hline Age & & & & 0.267 & & & 0.104 & & & 0.08 \\
\hline (years) & 64 & 37 & 27 & & 36 & 28 & & 26 & 38 & 9 \\
\hline$\leq 60$ & 21 & 15 & 6 & & 16 & 5 & & 13 & 8 & \\
\hline \multicolumn{11}{|l|}{$>60$} \\
\hline Gender & & & & 0.198 & & & 0.289 & & & 0.88 \\
\hline Male & 56 & 37 & 19 & & 32 & 24 & & 26 & 30 & 8 \\
\hline Female & 29 & 15 & 14 & & 20 & 9 & & 13 & 16 & \\
\hline ECOG & & & & 1.000 & & & 1.000 & & & 1.00 \\
\hline$<2$ & 78 & 48 & 30 & & 48 & 30 & & 36 & 42 & 0 \\
\hline$\geq 2$ & 7 & 4 & 3 & & 4 & 3 & & 3 & 4 & \\
\hline B & & & & 0.004 & & & 0.288 & & & 0.02 \\
\hline symptom & 37 & 29 & 8 & & 25 & 12 & & 22 & 15 & 7 \\
\hline Yes & 48 & 23 & 25 & & 27 & 21 & & 17 & 31 & \\
\hline \multicolumn{11}{|l|}{ No } \\
\hline Extranod & & & & 0.373 & & & 0.436 & & & 0.66 \\
\hline al sites & 68 & 40 & 28 & & 43 & 25 & & 32 & 36 & 3 \\
\hline$<2$ & 17 & 12 & 5 & & 9 & 8 & & 7 & 10 & \\
\hline \multicolumn{11}{|l|}{$\geq 2$} \\
\hline LDH & & & & 0.056 & & & 0.145 & & & 0.06 \\
\hline Normal & 33 & 16 & 17 & & 17 & 16 & & 11 & 22 & 4 \\
\hline Elevated & 52 & 36 & 16 & & 35 & 17 & & 28 & 24 & \\
\hline $\begin{array}{l}\text { Ann-Arb } \\
\text { or stage }\end{array}$ & & & & 0.892 & & & 0.561 & & & $\begin{array}{l}0.45 \\
1\end{array}$ \\
\hline I - II & 42 & 26 & 16 & & 27 & 15 & & 21 & 21 & \\
\hline III-IV & 43 & 26 & 17 & & 25 & 18 & & 18 & 25 & \\
\hline IPI & & & & 0.186 & & & 0.886 & & & 0.80 \\
\hline $0-2$ & 60 & 34 & 26 & & 37 & 23 & & 27 & 33 & 0 \\
\hline $3-5$ & 25 & 18 & 7 & & 15 & 10 & & 12 & 13 & \\
\hline Hans & & & & 0.436 & & & 0.059 & & & 0.12 \\
\hline classificat & & & & & & & & & & 8 \\
\hline ion & 17 & 9 & 8 & & 7 & 10 & & 5 & 12 & \\
\hline GCB & 68 & 43 & 25 & & 45 & 23 & & 34 & 34 & \\
\hline Non-GCB & & & & & & & & & & \\
\hline Ki-67 & & & & 0.593 & & & 0.680 & & & 0.94 \\
\hline High & 57 & 36 & 21 & & 34 & 23 & & 26 & 31 & 4 \\
\hline Low & 28 & 16 & 12 & & 18 & 10 & & 13 & 15 & \\
\hline Relapse & & & & 0.001 & & & 0.000 & & & 0.00 \\
\hline Yes & 54 & 40 & 14 & & 41 & 13 & & 32 & 22 & 1 \\
\hline No & 31 & 12 & 19 & & 11 & 20 & & 7 & 24 & \\
\hline
\end{tabular}

IPI, international prognostic index; GCB, germinal center B-cell-like lymphoma.

\section{Correlation of EZH2 and Bcl-2 expression with clinicopathologic parameters.}

According to the X-tile plots, we dichotomized the samplels into low (IRS $\leq 6)$ and high (IRS >6) EZH2 expression subgroups $(P=0.021$; Fig. $2 \mathrm{~A}-\mathrm{C})$. High EZH2 expression was observed in $61.2 \%(52 / 85)$ DLBCL patients in test cohort and $70.6 \%(36 / 51)$ in validation cohort. Correlation analysis demonstrated that high expression of EZH2 was significantly associated with presence of $B$ symptom and relapse $(P=0.004$ and 0.001 , respectively; Table 1$)$, and marginally associated with elevated LDH level $(P=0.056)$. There was no significant association between EZH2 expression and other clinicopathologic parameters, such as patients' age, gender, stage or Hans classification (all $P>0.05$, Table 1). In the test cohort, high expression of Bcl-2 and Ki-67 were observed in 61.2\% (52/85) and 67.1\% (57/85) DLBCL patients, respectively. While in the validation cohort, high expression of Bcl-2 was observed in 58.8\%
(30/51) patients and coexpression of EZH2/Bcl-2 was found in 39.2\% (20/51) patients. High expression of Bcl-2 was aslo significantly associated with disease relapse $(P=0.000)$. With regard to the positive correlation between EZH2 and Bcl-2 expression and both of them were closely correlated with the outcome of disease, we tried to use coexpression of EZH2 and Bcl-2 as a predictor for the outcome of DLBCL and test its efficacy, and found that just like EZH2 did, coexpression of EZH2 and Bcl-2 was significantly associated with presence of $B$ symptom and relapse $(P=0.027$ and 0.001 , respectively; Table 1$)$, and marginally associated with elevated LDH level $(P=0.064)$. There was no significant association between EZH2/Bcl-2 coexpression and other clinicopathologic parameters like age, gender, stage or Hans classification (all $P>0.05$, Table 1).

\section{Treatment, response to regimens and outcome}

Number of patients receiving RCHOP and $\mathrm{CHOP}$ regimen was 41 and 44, respectively. Except for the B symptom $(P=0.010)$, patients' characteristics distribution in both subgroups was well balanced $(P>0.05$, Table 2). The ORR (CR + PR) in CHOP and RCHOP groups was $45.5 \%(20 / 44)$ and $80.5 \%$ (33/41), respectively.

Table 2. Patient's features according to the treatment in test cohort.

\begin{tabular}{llll}
\hline & $\begin{array}{l}\text { RCHOP } \\
(\mathrm{n}=41)\end{array}$ & $\begin{array}{l}\text { CHOP } \\
(\mathrm{n}=44)\end{array}$ & P-value \\
\hline Age range & $26-78$ & $24-76$ & \\
Age $>60$ years, $\mathrm{n}$ & $11(27 \%)$ & $10(23 \%)$ & 0.661 \\
Male/female, $\mathrm{n}$ & $28 / 13(68 / 32 \%)$ & $28 / 16(64 / 36 \%)$ & 0.651 \\
ECOG $\geq 2, \mathrm{n}$ & $3(7 \%)$ & $4(9 \%)$ & 1.000 \\
B symptom, $\mathrm{n}$ & $12(29 \%)$ & $25(57 \%)$ & 0.010 \\
Extranodal sites, $\mathrm{n}$ & $6(15 \%)$ & $11(25 \%)$ & 0.233 \\
LDH>1×normal, $\mathrm{n}$ & $23(56 \%)$ & $29(66 \%)$ & 0.354 \\
Ann-Arbor stage & $20(49 \%)$ & $23(52 \%)$ & 0.748 \\
III-IV, $\mathrm{n}$ & & & 0.145 \\
IPI 3-5, $\mathrm{n}$ & $9(22 \%)$ & $16(36 \%)$ & 0.129 \\
Hans classification & $11(27 \%)$ & $6(14 \%)$ & 0.247 \\
GCB, $\mathrm{n}$ & & & \\
Ki-67 $>75 \%, \mathrm{n}$ & $30(73 \%)$ & $27(61 \%)$ & \\
\hline
\end{tabular}

As shown in Table 3, that in the CHOP group, the prognostic factors that were significantly correlated, by univariate analysis, with response to treatment were EZH2 high expression $(P=0.042)$, age $>60$ years $(P=0.013)$, elevated LDH $(P<0.001)$, advanced stage III-IV $(P=0.001), \geq 2$ Extranodal sites $(P=0.006)$, IPI 3-5 $(P<0.001)$ and B symptom $(P<0.001)$. While in the RCHOP group, however, the situation was quite different. For only presence of $\mathrm{B}$ symtom and EZH2/BCL-2 coexpression was found to be significantly associated with inferior 
chemotherapeutic response in DLBCL patients $(P$ $=0.034$ and 0.013 , respectively), while other factors like EZH2 alone, age, elevated LDH and so forth were statistically excluded (Table 4), which was quite different from the prognostic pattern in $\mathrm{CHOP}$ group.

Table 3. Prognostic factors and treatment response in DLBCL patients in test cohort treated with $\mathrm{CHOP}$ or $\mathrm{CHOP}$-like regimen.

\begin{tabular}{lll}
\hline Prognostic factors & ORR, $\%$ & $P$ \\
\hline EZH2 expression, high vs. low & 34 vs. 67 & 0.042 \\
Age $>60$ vs. $\leq 60$ & 10 vs. 56 & 0.013 \\
LDH, elevated vs. normal & 17 vs. 100 & 0.000 \\
Ann-Arbor stage, III-IV vs. I - II & 22 vs. 71 & 0.001 \\
Extranodal sites, $\geq 2$ vs. $<2$ & 9 vs. 58 & 0.006 \\
IPI, $3-5$ vs. $0-2$ & 6 vs. 68 & 0.000 \\
B symptom, yes vs. no & 20 vs. 79 & 0.000 \\
\hline
\end{tabular}

Table 4. Prognostic factors and treatment response in DLBCL patients in test cohort treated with RCHOP or RCHOP-like regimen.

\begin{tabular}{lll}
\hline Prognostic factors & ORR, $\%$ & $P$ \\
\hline B symptom, yes vs. no & 20 vs. 79 & 0.034 \\
EZH2/Bcl-2 coexpression, yes vs. & 61 vs. 95 & 0.013 \\
no & & \\
\hline
\end{tabular}

\section{Prognostic analyses}

In the CHOP group of test cohort, the 3-year PFS and 5-year OS rate was both $36.4 \%$. Univariate survival analysis revealed factors like age $>60$ years $(P=0.001), \quad \geq 2 \quad$ ECOG $(P=0.025)$, elevated LDH $(P<0.001)$, stage III-IV $(P<0.001), \geq 2$ extranodal sites $(P=0.002)$, IPI 3-5 $(P<0.001)$, B symptom $(P=0.003)$ and high $\mathrm{Bcl}-2$ expression $(P=0.029)$ were significantly associated with negative outcomes and shorter PFS. While multivariate analysis indicated factors related to worse PFS were elevated LDH level $(P=0.000)$, IPI 3-5 $(P=0.014)$, presence of $\mathrm{B}$ symtom $(P=0.017)$ and high Bcl-2 expression $(P=0.003$, Table 5$)$. In the analyses on factors associated with OS using Cox proportional model, however, univariate analysis determined that age $>60$ years $(P=0.001), \geq 2$ ECOG $(P=0.009)$, elevated LDH $(P=0.001)$, stage III-IV $(P=0.000), \quad \geq 2$ extranodal sites $(P=0.001)$, IPI $3-5(P=0.000)$ and $\mathrm{B}$ symptom $(P=0.001)$ were closely significant while high $\mathrm{Bcl}-2$ expression was marginally correlated $(P=0.050)$. Multivariate analysis indicated that only elevated LDH level $(P=0.001)$ and presence of B symtom $(P=0.008)$ were associated with worse OS (Table 5).

In the RCHOP group, 5-year OS and 3-year PFS were $68.3 \%$ and $65.9 \%$, respectively. The prognostic factors with a negative impact on PFS by univariate analysis were elevated LDH $(P=0.006)$, high EZH2 expression $(P=0.008)$, high Bcl-2 expression $(P=0.006)$ and EZH2/Bcl-2 coexpression $(P=0.002)$, and by multivariate analysis were elevated LDH $(P=0.001)$ and high $\mathrm{Bcl}-2$ expression $(P=0.002)$. The prognostic factors with a negative impact on OS by univariate analysis were elevated LDH $(P=0.005)$, high $\mathrm{Bcl}-2$ expression $(P=0.017)$ and $\mathrm{EZH} 2 / \mathrm{Bcl}-2$ coexpression $(P=0.025)$, and by multivariate analysis were elevated LDH $(P=0.004)$ and high Bcl-2 expression $(P=0.014$, Table 6).

Table 5. Prognostic factors and PFS/OS in DLBCL patients in test cohort treated with $\mathrm{CHOP}$ or $\mathrm{CHOP}-$ like regimen.

\begin{tabular}{|c|c|c|c|c|c|c|}
\hline \multirow[t]{2}{*}{ Prognostic factors } & \multicolumn{3}{|c|}{ Univariate analysis } & \multicolumn{3}{|c|}{ Multivariate analysis } \\
\hline & $\overline{\mathrm{HR}}$ & $95 \% \mathrm{CI}$ & $P$ & HR & $95 \% \mathrm{CI}$ & $P$ \\
\hline \multicolumn{7}{|l|}{$\begin{array}{l}\text { Progression-free } \\
\text { survival }\end{array}$} \\
\hline Age ( $\leq 60$ vs. $>60$ y.o.) & 3.806 & $1.687-8.588$ & 0.001 & - & - & - \\
\hline $\operatorname{ECOG}(<2 v s . \geq 2)$ & 3.581 & $1.178-10.882$ & 0.025 & - & - & - \\
\hline $\begin{array}{l}\text { LDH (normal vs. } \\
\text { elevated) }\end{array}$ & 22.052 & $5.069-95.938$ & 0.000 & 20.325 & $4.060-101.749$ & 0.000 \\
\hline Stage (I-II vs. III-IV) & 5.843 & $2.470-13.822$ & 0.000 & - & - & - \\
\hline $\begin{array}{l}\text { Extranodal sites }(<2 \\
\text { vs. } \geq 2)\end{array}$ & 3.622 & $1.585-8.279$ & 0.002 & - & - & - \\
\hline IPI (0-2 vs. 3-5) & 7.233 & $2.933-17.837$ & 0.000 & 3.240 & $1.268-8.279$ & 0.014 \\
\hline $\begin{array}{l}\text { B symptom (no vs. } \\
\text { yes) }\end{array}$ & 3.246 & $1.496-7.044$ & 0.003 & 3.130 & $1.231-7.957$ & 0.017 \\
\hline $\begin{array}{l}\text { Bcl-2 expression } \\
\text { (high vs. low) }\end{array}$ & 2.490 & $1.099-5.640$ & 0.029 & 4.362 & $1.646-11.561$ & 0.003 \\
\hline \multicolumn{7}{|l|}{ Overall survival } \\
\hline Age ( $\leq 60$ vs. $>60$ y.o. $)$ & 4.355 & $1.896-10.005$ & 0.001 & - & - & - \\
\hline $\operatorname{ECOG}(<2$ vs. $\geq 2)$ & 4.707 & $1.466-15.108$ & 0.009 & - & - & - \\
\hline $\begin{array}{l}\text { LDH (normal vs. } \\
\text { elevated) }\end{array}$ & 35.585 & $4.753-266.397$ & 0.001 & 32.220 & $4.259-243.736$ & 0.001 \\
\hline Stage (I-II vs. III-IV) & 4.916 & $2.048-11.803$ & 0.000 & - & - & - \\
\hline $\begin{array}{l}\text { Extranodal sites }(<2 \\
\text { vs. } \geq 2)\end{array}$ & 3.649 & $1.652-8.063$ & 0.001 & - & - & - \\
\hline IPI (0-2 vs. 3-5) & 6.134 & $2.692-13.973$ & 0.000 & - & - & - \\
\hline $\begin{array}{l}\text { B symptom (no vs. } \\
\text { yes) }\end{array}$ & 4.114 & $1.781-9.502$ & 0.001 & 3.247 & $1.354-7.787$ & 0.008 \\
\hline $\begin{array}{l}\text { Bcl-2 expression } \\
\text { (high vs. low) }\end{array}$ & 2.363 & $1.000-5.588$ & 0.050 & - & - & - \\
\hline
\end{tabular}

Table 6. Prognostic factors and PFS/OS in DLBCL patients in test cohort treated with RCHOP or RCHOP-like regimen.

\begin{tabular}{|c|c|c|c|c|c|c|}
\hline \multirow[t]{2}{*}{ Prognostic factors } & \multicolumn{3}{|c|}{ Univariate analysis } & \multicolumn{3}{|c|}{ Multivariate analysis } \\
\hline & HR & $95 \% \mathrm{CI}$ & $P$ & HR & $95 \% \mathrm{CI}$ & $P$ \\
\hline \multicolumn{7}{|l|}{$\begin{array}{l}\text { Progression-free } \\
\text { survival }\end{array}$} \\
\hline $\begin{array}{l}\text { LDH (normal vs. } \\
\text { elevated) }\end{array}$ & 3.512 & $1.435-8.595$ & 0.006 & 4.631 & $1.818-11.800$ & 0.001 \\
\hline $\begin{array}{l}\text { EZH2 expression (high } \\
\text { vs. low) }\end{array}$ & 3.544 & $1.397-8.992$ & 0.008 & - & - & - \\
\hline $\begin{array}{l}\text { Bcl-2 expression (high } \\
\text { vs. low) }\end{array}$ & 3.974 & $1.473-10.724$ & 0.006 & 5.174 & $1.857-14.414$ & 0.002 \\
\hline $\begin{array}{l}\mathrm{EZH} 2 / \mathrm{Bcl}-2 \\
\text { coexpression (yes vs. no) }\end{array}$ & 3.682 & $1.595-8.499$ & 0.002 & - & - & - \\
\hline \multicolumn{7}{|l|}{ Overall survival } \\
\hline $\begin{array}{l}\text { LDH (normal vs. } \\
\text { elevated) }\end{array}$ & 5.913 & $1.703-20.535$ & 0.005 & 6.178 & $1.772-21.540$ & 0.004 \\
\hline $\begin{array}{l}\text { Bcl-2 expression (high } \\
\text { vs. low) }\end{array}$ & 4.568 & $1.318-15.833$ & 0.017 & 4.799 & $1.379-16.694$ & 0.014 \\
\hline $\begin{array}{l}\mathrm{EZH} 2 / \mathrm{Bcl}-2 \\
\text { coexpression (yes vs. no) }\end{array}$ & 2.968 & $1.146-7.691$ & 0.025 & - & - & - \\
\hline
\end{tabular}


EZH2 and Bcl-2 protein coexpression had a significantly adverse impact on OS and PFS in DLBCL patients (Fig. 2D-E). The 5-year OS of EZH2/BCL-2 coexpression vs. noncoexpression was $35.9 \%$ vs. $65.2 \%(P=0.006)$ and the 3-year PFS was $33.3 \%$ vs $65.2 \%(P=0.0005)$. DLBCL patients with either high EZH2 expression or Bcl-2 expression also had significantly inferior OS $(P=0.021$ or $P=0.001)$ and PFS $(P=0.002$ or $P<0.001$; Fig. $2 \mathrm{~F}-\mathrm{G})$, respectively. When the EZH2/Bcl-2 coexpression cases were excluded, EZH2 expression demonstrated no correlation with OS at all $(P=0.584)$ while high Bcl-2 expression remained effective on inferior OS $(P=0.024$, Fig. $2 \mathrm{H}-\mathrm{I})$.

In the validation cohort, same results had been observed. That's, DLBCL patients with EZH2/Bcl-2 coexpression had a significantly shorter OS (Fig. 3A, $P<0.0001)$ and DLBCL patients with either high EZH2 expression $(P=0.0102)$ or $\mathrm{Bcl}-2$ expression $(P=0.0475)$ also had significantly inferior OS (Fig. 3B-C).

No significant difference in OS $(P=0.120)$ or PFS $(P=0.082)$ had been determined between patients' subgroups of EZH2/Bcl-2 coexpression and noncoexpression who'd both received the CHOP regimen, although patients with coexpression might incline to have adverse survival ( $P=0.082$, Fig. 3D-E). Nevertheless, EZH2/Bcl-2 coexpression patients receiving RCHOP regimen showed shorter OS $(P=0.019)$ and PFS $(P=0.001)$ compared to the noncoexpression patients (Fig. 3F-G).
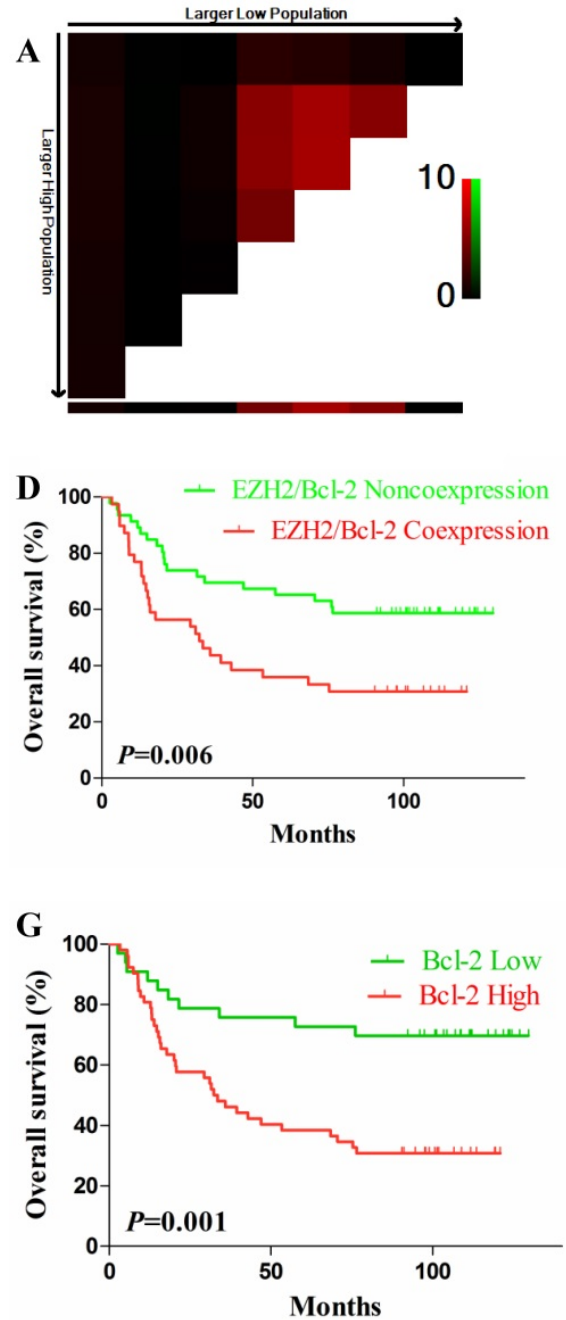
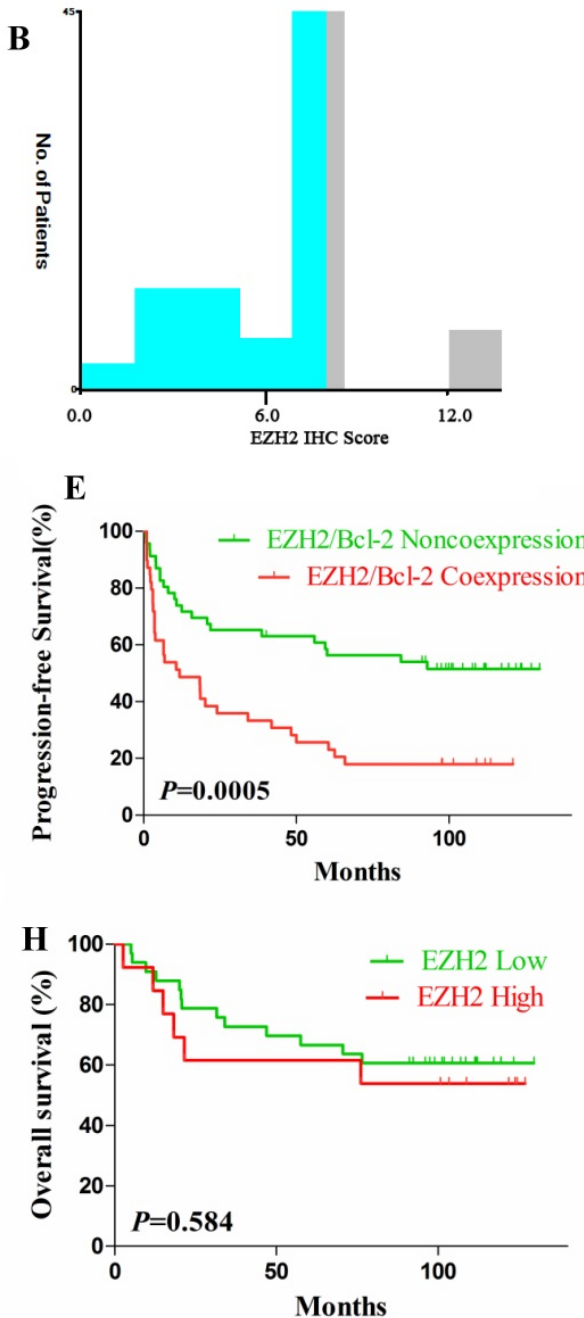
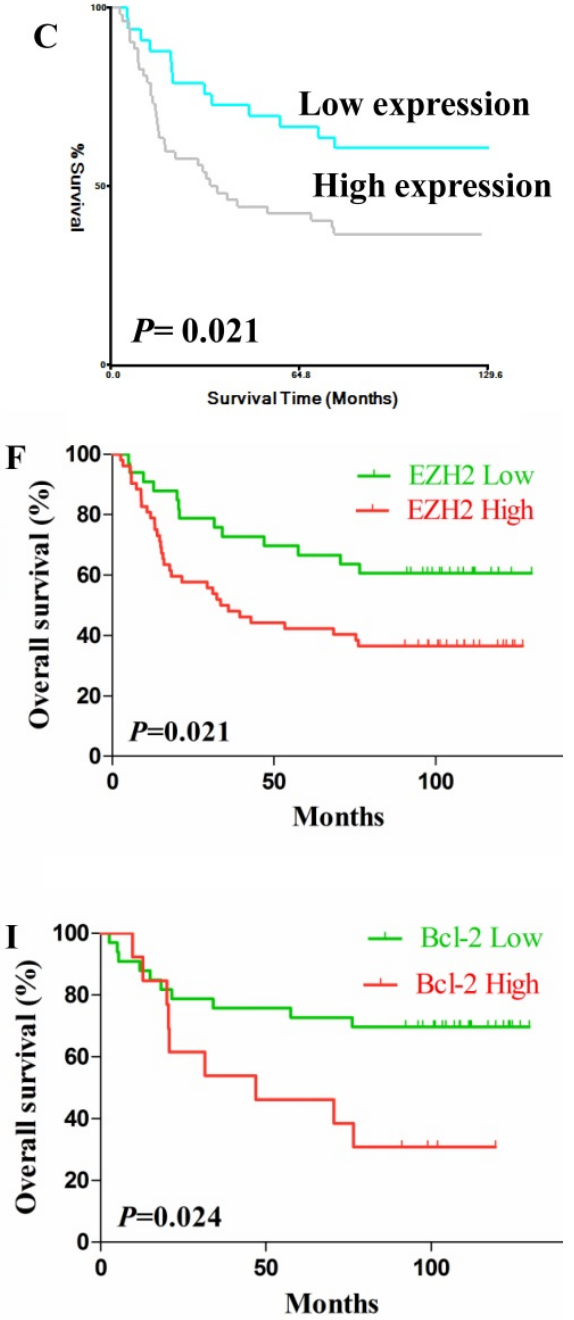

Figure 2. X-tile plots of EZH2 expression for optimal cut-off determination and prognostic impact of EZH2 and Bcl-2 expression in test cohort. (A-B) The cut-off (IRS=6, $P=0.021$ ) was used to separate low $E Z H 2$ expression (blue) from high (gray) in the frequency histogram of whole samples. (C) Kaplan-Meier curve for testing the survival of sample subsets defined by $E Z H 2$ expression under (blue line) and above 6 (gray line). (D-E). OS (D) and PFS (E) of DLBCL patients with EZH2/Bcl-2 coexpression. (F-G). OS of patients with high expression of EZH2 (F) or Bcl-2 (G). (H-I). OS of patients with high expression of EZH2 (H) or Bcl-2 (I) when the cases with EZH2/Bcl-2 coexpression were excluded. 
Generally, patients receiving RCHOP regimen showed longer OS (HR 0.4511, 95\% CI of ratio: 0.2502-0.8132) compared with those receiving CHOP $(P=0.008$, Fig. $4 \mathrm{~A})$ while nearly no difference was found in PFS within groups $(P=0.057)$. Further analyses indicated that, firstly, in the EZH2/Bcl-2 noncoexpression group patients receiving $\mathrm{RCHOP}$ regimen demonstrated longer $\mathrm{OS}$ in comparison to CHOP $(P=0.044$, Fig. 4B). Secondly, in the EZH2/BCL-2 coexpression group, no difference was found either in OS or PFS between the two therapeutic regimens $(P=0.099$ and $P=0.341$, Fig. $4 \mathrm{D}-\mathrm{E})$. Moreover, in the coexpression DLBCL patients no difference was found in localized lesions (stageI/II) ( $\mathrm{P}=0.607$ and $\mathrm{P}=0.685$; Fig. 4F-G), while in patients at a stage of III/IV, a statistically significant difference $(P=0.039$ and $P=0.005)$ was found in OS and PFS between the RCHOP and CHOP regimen groups (Fig. 4H-I).

\section{Discussion}

In the present study, we demonstrated that DLBCL patients with high level of either EZH2 or Bcl-2 exhibited a worse outcome, and the prognosis was even worse for those with simultaneous expression of EZH2 and Bcl-2 (Fig. 2D-G). Further analyses indicated that DLBCL patients with both high level of EZH2 and Bcl-2 seemed barely to benefit from the regimen with rituximab (R-CHOP), especially in early-staged patients (Fig. 4F, G).
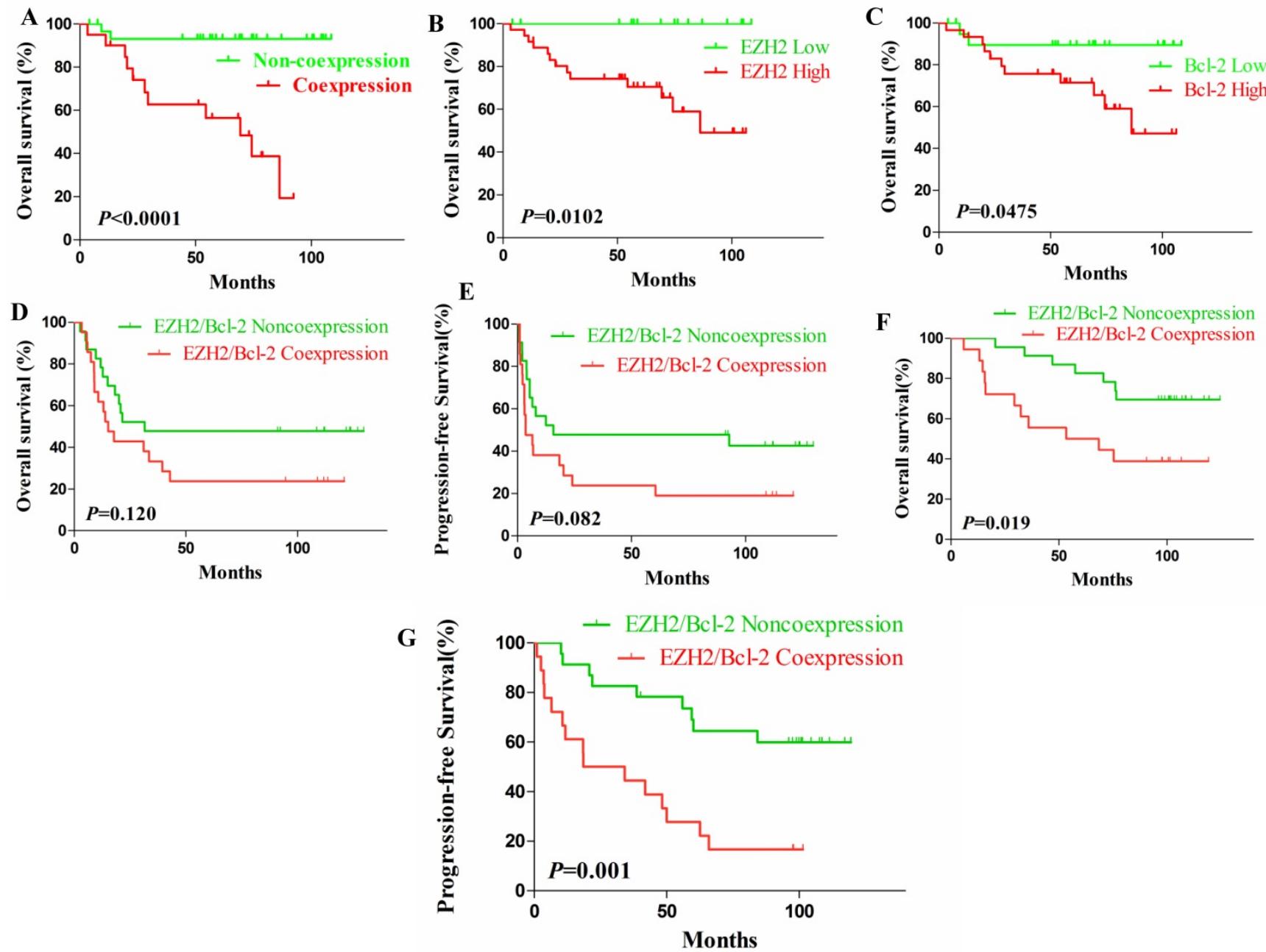

Figure 3. The survival curves of validation cohort and survival analysis of EZH2/BCL-2 coexpression and noncoexpression DLBCL patients in test cohort with different treatments. (A-C). In the validation cohort, DLBCL patients with EZH2/BCL-2 coexpression (A) exhibited worse outcome and shorter OS in comparison to those without; In addition, patients with high level of either EZH2 (B) or Bcl-2 (C) exhibited short OS compared to those with low levels. (D-E).The OS (D) and PFS (E) between the EZH2/BCL-2 coexpression and noncoexpression DLBCL patients who received CHOP regimen. (F-G).The OS (F) and PFS (G) between the EZH2/BCL-2 coexpression and noncoexpression DLBCL patients who received RCHOP regimen. 

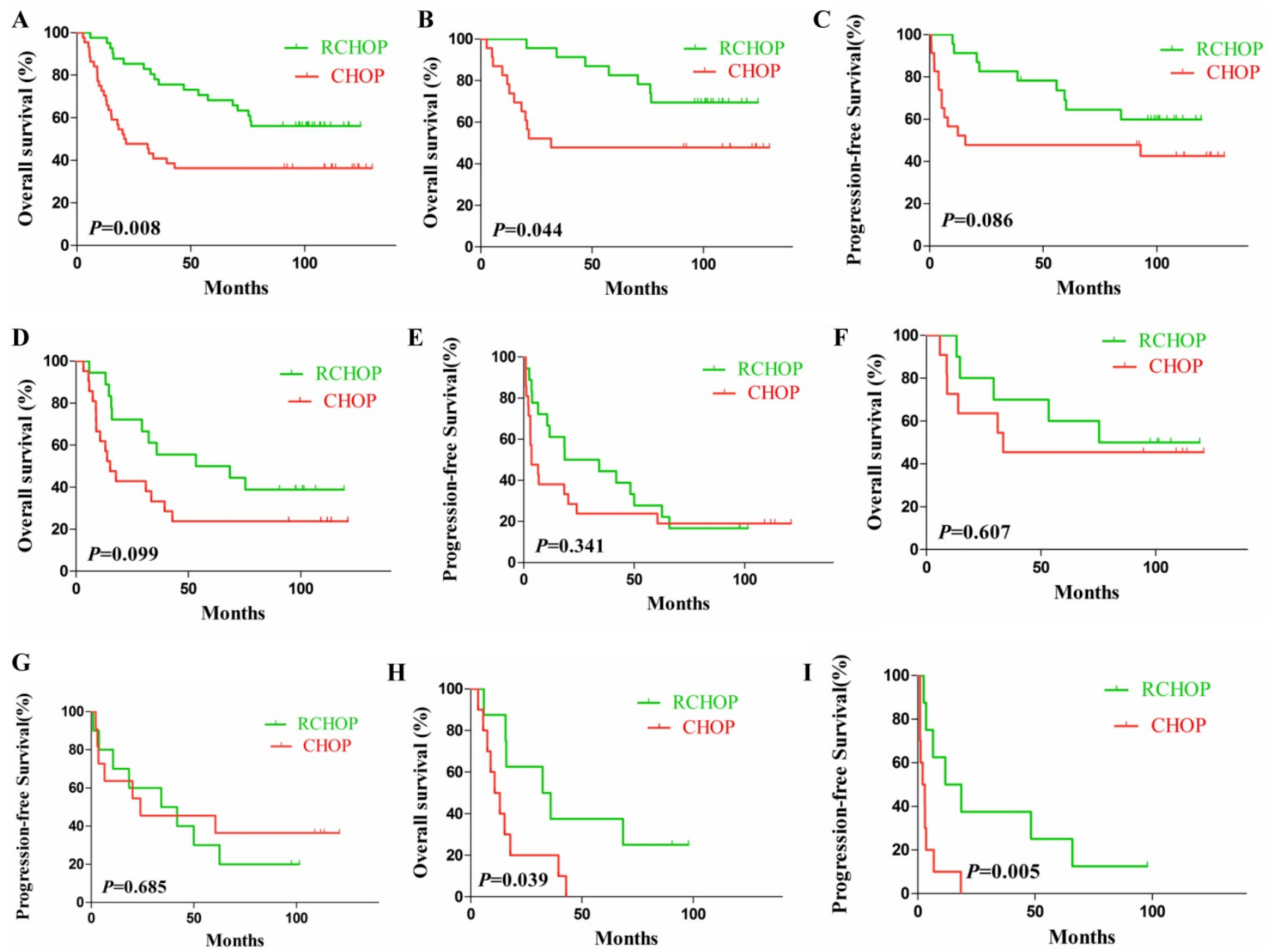

Figure 4. Kaplan-Meier analysis of OS and PFS in test cohort according to different therapeutic modalities. (A). OS of patients receiving RCHOP regimen was longer than that of CHOP; (B-C). OS (B) and PFS (C) of noncoexpression DLBCL patients by RCHOP and CHOP regimen. (D-E). OS (D) and PFS (E) of EZH2/Bcl-2 coexpression DLBCL patients by different treatments. (F-G). OS (F) and PFS (G) of stage I - II EZH2/Bcl-2 coexpression DLBCL patients by RCHOP and CHOP regimen. $(\mathrm{H}-\mathrm{I})$. OS $(\mathrm{H})$ and PFS (I) of stage III-IV EZH2/Bcl-2 coexpression DLBCL patients by RCHOP and CHOP regimen.

Our previous study had reported that most DLBCLs manesfested with high expression of trimethylated histone $\mathrm{H} 3$ at lysine 27 and had determined H3K27me3 as an independent risk factor in DLBCL patients, and its expression was found positively correlated with its methyltransferase---EZH2 [17, 18]. Besides, Bcl-2 protein is a well-established anti-apoptotic factor and plays a vital role in the onset as well as progression in DLBCL, and its overexpression has been proven as a pivotal risk factor in depicting the prognosis in lymphomas of various categories[26, 29-32]. In the present study, western blot analysis in 4 DLBCL cell lines TMD8, HBL-1, Ly1 and Ly8 also testified the stronger expression of $\mathrm{H} 3 \mathrm{~K} 27 \mathrm{me} 3, \mathrm{EZH} 2$ and $\mathrm{Bcl}-2$ in comparison to normal human peripheral blood lymphocyte and normal lymph node (Fig. 1J). Chi-square analysis indicated high level of EZH2 or Bcl-2 was closely correlated with relapse (both $P<0.01$, Table 1), which was one of the vital factors associated with prognosis. Survival analysis with log-rank tests in both test cohort and validation cohort indicated that patients with higher EZH2 or Bcl-2 level ended up with shorter OS. Since recently, Wang et al demonstrated that EZH2 knockdown induced apoptosis of human endometrial carcinoma cells by promoting the expression of pro-apoptosis protein caspase 3/9, Bcl-2 associated $\mathrm{X}$ and decreasing the expression of anti-apoptosis protein $\mathrm{Bcl}-2$, we thus used coexpression of $\mathrm{EZH} 2$ and $\mathrm{Bcl}-2$ as a new biomarker to testify its prognostic effect in the outcome of DLBCL patients and found that coexpression subgroup exhibited much worse PFS and OS in comparison to the non-coexpression (Fig. 2D, E and Fig. 3A). In addition, after excluding the EZH2/Bcl-2 coexpression population from the overall test cohort, only $\mathrm{Bcl}-2$ protein expression rather than EZH2 significantly impacted OS (Fig. 2H, I), indicating that EZH2 affected prognosis only in the presence of Bcl-2 coexpression. 
In connection with the results of therapeutic regimens, we found that in comparison to non-coexpression subgroup, DLBCL patients with EZH2/Bcl-2 coexpression in the RCHOP arm had a shorter PFS and OS, while in the CHOP arm no survival discrepancy had been observed within these two subgroups (Fig. 3D-G). As is well known to us all that rituximab is a chimeric monoclonal antibody that binds to the pan-B-cell marker CD20, which is expressed in $\sim 90 \%$ of B-cell lymphomas[33]. On engagement with CD20, rituximab kills target cells through complement-dependent cytotoxicity and antibody-dependent cellular cytotoxicity, as well as direct activation of the cell death program. RCHOP regimen had been proven to prevail over $\mathrm{CHOP}$ in the therapeutic outcome[34-36], as was also true in our study (Fig. 4A). Further analyses showed that when stratified into EZH2/Bcl-2 coexpression and non-coexpression subgroups, no significant difference had been determined for OS/PFS in either CHOP or RCHOP arm. However, when EZH2/Bcl-2 coexpression patients were further stratified into early (I-II) and advanced (III-IV) stages, we found that DLBCL patients in advanced stage could significantly benefit from the introduction of rituximab while the early-staged barely could. Interestingly, the RCHOP regimen related to the longer survival in the noncoxepression group, which were not found in the EZH2/Bcl-2 coexpression group. The addition of rituximab to $\mathrm{CHOP}$ chemotherapy seems unable to overcome the adverse prognostic effect of EZH2/Bcl-2 coexpression. Maybe EZH2/Bcl-2 coexpression has eliminated the role of chemotherapy combined with immunotherapy. To further investigate the relationship of the coexpression and treatments at regional or advanced stage of DLBCL patients, stage-matched survival analysis was performed. It was found that the RCHOP correlates statistically better OS and PFS than CHOP regimen at Ann-Arbor stage III-IV but did not in localized stage. Similarly, some other research also reported that the level of EZH2 or H3K27me3 expression correlates with prognosis with different stage in solid tumor[37]. So we concluded that treatment options for DLBCL might differ between EZH2/Bcl-2 coexpression patients with localized and advanced disease. There would have some important therapeutic implication that the RCHOP regimen would improve the survival of the EZH2/Bcl-2 protein coexpression DLBCL patients with advanced stage, however some more additional therapeutic targets might be suggested in the localized lesions in DLBCL.

$\mathrm{Bcl}-2$ rearrangement results in overexpression of the antiapoptotic Bcl-2 protein, involving in the regulation of programmed cell death, which plays an important role in tumorigenesis of B-cell lymphoma, induces to the chemotherapy resistance, and further accelerates lymphoma progression[38]. In our study, high Bcl-2 expression was observed in 58.8\% - $61.2 \%$ DLBCL patients and associated with poor survival, consistent with the results in other studies [39]. However, $B c l-2$ rearrangement alone or overexpression is not sufficient for malignant transformation of B-cells. The Bcl-2 overexpression can mediate the globally increased H3K27me3 cooperated with apoptotic resistance to accelerate B-cell transformation[40]. In human B-cell lymphoma, the co-occurrence of these genetic alterations can be confirmed [41]. We evaluated the expression status of EZH2 and Bcl-2 to determine whether there was a potential correlation between these two proteins and found that the expression level of EZH2 in the high Bcl-2 expression group was significantly higher than that in the low Bcl-2 expression group, which supported the view that the deregulation, increased expression of EZH2 via aberration of Bcl-2 in DLBCLs, might play a critical role in hematologic malignancies. Further, we assessed all the clinicopathologic parameters as predictors for treatment and survival in homogeneous groups of DLBCL patients treated with $\mathrm{CHOP}$ or RCHOP. It could also predict the same effect and poor treatment response in RCHOP group, in which the previously validated prognostic factor such as clinical stage or IPI may not work better [38, 42]. The predictor of ORR and survival in the CHOP group, such as age $>60$, elevated LDH level, stage III-IV, extranodal sites $\geq 2$ and IPI 3-5 did not predict treatment response to RCHOP therapy. Perhaps the new indicators could be used for prognosis depending on the mechanism of the effectiveness of immunochemotherapy.

In summary, our study evaluated the possibility of using coexpression of EZH2/Bcl-2 as a clinically potential prognostic marker in DLBCL. The up-regulation of EZH2 may be due to enhanced expression of Bcl-2 suggesting that $\mathrm{Bcl}-2$ might be involved in the PRC2-associated induction of H3K27me3 in DLBCLs. The combined Bcl-2 and EZH2 inhibition may represent a potential therapeutic implications. The results can help us identify a high-risk subgroup of newly diagnosed DLBCL and predict their prognosis, which may eventually develop new drug therapies.

\section{Acknowledgements}

This study was supported in part by Miaopu Research Foundation from Fujian Medical University (No. 2015MP032 to Y. Deng), Startup Foundation from Fujian Medical University (No. 2016QH040 to Y. Deng), National Foundation of Natural Science (No. 
81272628 to J. Chen and No. 81400160 to Z. Zeng), Fujian Foundation of Natural Science (No. 2017J01185 to Z. Zeng) and Science and Technology Program of Fujian Province, China (No. 2018Y2003 to X. Chen, C. Huang, G. Chen, C. He, J. Chen, R. Lin and Y. Chen). We thank Prof. Xiaoyan Zhou from Dept. of Molecular Pathology of Fudan University Cancer Hospital very much for her generous provision of DLBCL cell lines.

\section{Competing Interests}

The authors have declared that no competing interest exists.

\section{References}

1. Al-Hamadani M, Habermann TM, Cerhan JR, Macon WR, Maurer MJ, Go RS. Non-Hodgkin lymphoma subtype distribution, geodemographic patterns, and survival in the US: A longitudinal analysis of the National Cancer Data Base from 1998 to 2011. Am J Hematol. 2015; 90: 790-5.

2. Siegel RL, Miller KD, Jemal A. Cancer statistics, 2018. CA Cancer J Clin. 2018; 68: 7-30.

3. Ekberg S, Jerkeman M, Andersson PO, Enblad G, Wahlin BE, Hasselblom S, et al. Long-term survival and loss in expectancy of life in a population-based cohort of 7114 patients with diffuse large B-cell lymphoma. Am J Hematol.

2018,May 17. doi: 10.1002/ajh.25147. [Epub ahead of print]

4. Pfreundschuh M, Trumper L, Osterborg A, Pettengell R, Trneny M, Imrie K, et al. CHOP-like chemotherapy plus rituximab versus $\mathrm{CHOP}$-like chemotherapy alone in young patients with good-prognosis diffuse large-B-cell lymphoma: a randomised controlled trial by the MabThera International Trial (MInT) Group. Lancet Oncol. 2006; 7: 379-91.

5. Feugier P, Van Hoof A, Sebban C, Solal-Celigny P, Bouabdallah R, Ferme C, et al. Long-term results of the R-CHOP study in the treatment of elderly patients with diffuse large B-cell lymphoma: a study by the Groupe d'Etude des Lymphomes de l'Adulte. J Clin Oncol. 2005; 23: 4117-26.

6. Kohrt HE, Thielens A, Marabelle A, Sagiv-Barfi I, Sola C, Chanuc F, et al Anti-KIR antibody enhancement of anti-lymphoma activity of natural killer cells as monotherapy and in combination with anti-CD20 antibodies. Blood. 2014; 123: 678-86.

7. Zhou Z, Gao J, Popovic R, Wolniak K, Parimi V, Winter JN, et al. Strong expression of EZH2 and accumulation of trimethylated H3K27 in diffuse large B-cell lymphoma independent of cell of origin and EZH2 codon 641 mutation. Leuk Lymphoma. 2015; 56: 2895-901.

8. Oh EJ, Kim SH, Yang WI, Ko YH, Yoon SO. Long Non-coding RNA HOTAIR Expression in Diffuse Large B-Cell Lymphoma: In Relation to Polycomb Repressive Complex Pathway Proteins and H3K27 Trimethylation. J Pathol Transl Med. 2016; 50: 369-76.

9. McCabe MT, Ott HM, Ganji G, Korenchuk S, Thompson C, Van Aller GS, et al. EZH2 inhibition as a therapeutic strategy for lymphoma with EZH2-activating mutations. Nature 2012: 492:108-12.

10. Zheng W, Yu A. EZH2-mediated suppression of lncRNA-LET promotes cell apoptosis and inhibits the proliferation of post-burn skin fibroblasts. Int J Mol Med. 2018; 41: 1949-57.

11. Chase A, Cross NC. Aberrations of EZH2 in cancer. Clin Cancer Res. 2011; 17: 2613-8.

12. Chen X, Song N, Matsumoto K, Nanashima A, Nagayasu T, Hayashi T, et al. High expression of trimethylated histone $\mathrm{H} 3$ at lysine 27 predicts better prognosis in non-small cell lung cancer. Int J Oncol. 2013; 43: 1467-80.

13. Iqbal J, Neppalli VT, Wright G, Dave BJ, Horsman DE, Rosenwald A, et al. BCL2 expression is a prognostic marker for the activated B-cell-like type of diffuse large B-cell lymphoma. J Clin Oncol. 2006; 24: 961-8.

14. Ryan RJ, Nitta M, Borger D, Zukerberg LR, Ferry JA, Harris NL, et al. EZH2 codon 641 mutations are common in BCL2-rearranged germinal center B cell lymphomas. PLoS One. 2011; 6: e28585.

15. Morin RD, Johnson NA, Severson TM, Mungall AJ, An J, Goya R, et al. Somatic mutations altering EZH2 (Tyr641) in follicular and diffuse large B-cell lymphomas of germinal-center origin. Nat Genet. 2010; 42: 181-5.

16. Rosenwald A, Wright G, Chan WC, Connors JM, Campo E, Fisher RI, et al. The use of molecular profiling to predict survival after chemotherapy for diffuse large-B-cell lymphoma. N Engl J Med. 2002; 346: 1937-47.

17. Deng YJ, Chen G, Zhu WF, Rui HB, Hong HL, Chen JM. [Expression and Prognostic Significance of H3K27 Trimethylation Protein in DLBCL]. Zhongguo Shi Yan Xue Ye Xue Za Zhi. 2016; 24: 1379-85.

18. Deng YJ, Chen G, Zhu WF, Chen XH, Hong HL, Huang LM, et al. [Significance of H3K27me3 and EZH2 in Predicting the Therapeutic Efficacy of Diffuse Large B-Cell Lymphoma]. Zhongguo Shi Yan Xue Ye Xue Za Zhi. 2018; 26: $159-65$.
19. Delsol G. [The 2008 WHO lymphoma classification]. Ann Pathol. 2008; 28 Spec No 1: S20-4

20. Cheson BD, Fisher RI, Barrington SF, Cavalli F, Schwartz LH, Zucca E, et al. Recommendations for initial evaluation, staging, and response assessment of Hodgkin and non-Hodgkin lymphoma: the Lugano classification. J Clin Oncol. 2014; 32: 3059-68.

21. Ilyas M, Grabsch H, Ellis IO, Womack C, Brown R, Berney D, et al. Guidelines and considerations for conducting experiments using tissue microarrays. Histopathology. 2013; 62: 827-39.

22. Chen X, Deng Y, Shi Y, Zhu W, Cai Y, Xu C, et al. Loss of expression rather than cytoplasmic mislocalization of RUNX3 predicts worse outcome in non-small cell lung cancer. Oncol Lett. 2018; 15: 5043-55.

23. Stollberg S, Kammerer D, Neubauer E, Schulz S, Simonitsch-Klupp I, Kiesewetter B, et al. Differential somatostatin and CXCR4 chemokine receptor expression in MALT-type lymphoma of gastric and extragastric origin. J Cancer Res Clin Oncol. 2016; 142: 2239-47.

24. Remmele $W$, Stegner HE. [Recommendation for uniform definition of an immunoreactive score (IRS) for immunohistochemical estrogen receptor detection (ER-ICA) in breast cancer tissue]. Pathologe. 1987; 8: 138-40.

25. Camp RL, Dolled-Filhart M, Rimm DL. X-tile: a new bio-informatics tool for biomarker assessment and outcome-based cut-point optimization. Clin Cancer Res. 2004; 10: 7252-9.

26. Jovanovic MP, Jakovic L, Bogdanovic A, Markovic O, Martinovic VC, Mihaljevic B. Poor outcome in patients with diffuse large B-cell lymphoma is associated with high percentage of bcl-2 and Ki 67-positive tumor cells. Vojnosanit Pregl. 2009; 66: 738-43.

27. Gaudio F, Giordano A, Perrone T, Pastore D, Curci P, Delia M, et al. High Ki67 index and bulky disease remain significant adverse prognostic factors in patients with diffuse large B cell lymphoma before and after the introduction of rituximab. Acta Haematol. 2011; 126: 44-51.

28. Hans CP, Weisenburger DD, Greiner TC, Gascoyne RD, Delabie J, Ott G, et al. Confirmation of the molecular classification of diffuse large B-cell lymphoma by immunohistochemistry using a tissue microarray. Blood. 2004; 103: 275-82.

29. Tsujimoto $\mathrm{Y}$, Cossman J, Jaffe E, Croce CM. Involvement of the bcl-2 gene in human follicular lymphoma. Science. $1985 ; 228: 1440-3$.

30. Aisenberg AC, Wilkes BM, Jacobson JO. The bcl-2 gene is rearranged in many diffuse B-cell lymphomas. Blood. 1988; 71: 969-72.

31. Reed JC, Cuddy M, Slabiak T, Croce CM, Nowell PC. Oncogenic potential of bcl-2 demonstrated by gene transfer. Nature. 1988; 336: 259-61.

32. Vaux DL, Cory S, Adams JM. Bcl-2 gene promotes haemopoietic cell survival and cooperates with c-myc to immortalize pre-B cells. Nature. 1988; 335: 440-2.

33. Martyniszyn A, Krahl AC, Andre MC, Hombach AA, Abken H. CD20-CD19 Bispecific CAR T Cells for the Treatment of B-Cell Malignancies. Hum Gene Ther. 2017; 28: 1147-57.

34. Morschhauser F, Salles G, Le Gouill S, Tilly H, Thieblemont C, Bouabdallah K, et al. An open-label, phase Ib study of obinutuzumab plus lenalidomide in relapsed/refractory follicular B-cell lymphoma. Blood. 2018;132:1486-94.

35. Karmali R, Kimby E, Ghielmini M, Flinn IW, Gordon LI, Zucca E. Rituximab: a benchmark in the development of chemotherapy-free treatment strategies for follicular lymphomas. Ann Oncol. 2018; 29: 332-40.

36. Huet S, Tesson B, Jais JP, Feldman AL, Magnano L, Thomas E, et al. A gene-expression profiling score for prediction of outcome in patients with follicular lymphoma: a retrospective training and validation analysis in three international cohorts. Lancet Oncol. 2018; 19: 549-61.

37. Liu $\mathrm{L}, \mathrm{Xu} \mathrm{Z}$, Zhong $\mathrm{L}$, Wang $\mathrm{H}$, Jiang $\mathrm{S}$, Long $\mathrm{Q}$, et al. Prognostic value of EZH2 expression and activity in renal cell carcinoma: a prospective study. PLoS One. 2013; 8: e81484.

38. Mounier $\mathrm{N}$, Briere $\mathrm{J}$, Gisselbrecht $\mathrm{C}$, Emile JF, Lederlin $\mathrm{P}$, Sebban $\mathrm{C}$, et al. Rituximab plus CHOP (R-CHOP) overcomes bcl-2--associated resistance to chemotherapy in elderly patients with diffuse large B-cell lymphoma (DLBCL). Blood. 2003; 101: 4279-84.

39. Guo S, Chan JK, Iqbal J, McKeithan T, Fu K, Meng B, et al. EZH2 mutations in follicular lymphoma from different ethnic groups and associated gene expression alterations. Clin Cancer Res. 2014; 20: 3078-86.

40. Souroullas GP, Jeck WR, Parker JS, Simon JM, Liu JY, Paulk J, et al. An oncogenic Ezh2 mutation induces tumors through global redistribution of histone 3 lysine 27 trimethylation. Nat Med. 2016; 22: 632-40.

41. Morin RD, Mendez-Lago M, Mungall AJ, Goya R, Mungall KL, Corbett RD, et al. Frequent mutation of histone-modifying genes in non-Hodgkin lymphoma. Nature. 2011; 476: 298-303.

42. Czuczman MS, Grillo-Lopez AJ, Alkuzweny B, Weaver R, Larocca A, McLaughlin P. Prognostic factors for non-Hodgkin's lymphoma patients treated with chemotherapy may not predict outcome in patients treated with rituximab. Leuk Lymphoma. 2006; 47: 1830-40. 